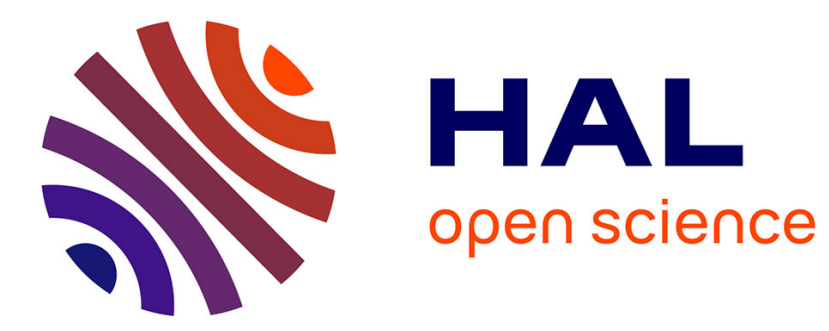

\title{
Fluorescent silver oligomeric clusters and colloidal particles
}

Mona Tréguer-Delapierre, Frédéric Rocco, Gérald Lelong, Anne Le Nestour, Thierry Cardinal, Abdelhamid Maali, Brahim Lounis

\section{- To cite this version:}

Mona Tréguer-Delapierre, Frédéric Rocco, Gérald Lelong, Anne Le Nestour, Thierry Cardinal, et al.. Fluorescent silver oligomeric clusters and colloidal particles. Solid State Sciences, 2005, 7 (7), pp.812-818. 10.1016/j.solidstatesciences.2005.01.017 . hal-00015003

\section{HAL Id: hal-00015003 https://hal.science/hal-00015003}

Submitted on 1 Dec 2005

HAL is a multi-disciplinary open access archive for the deposit and dissemination of scientific research documents, whether they are published or not. The documents may come from teaching and research institutions in France or abroad, or from public or private research centers.
L'archive ouverte pluridisciplinaire HAL, est destinée au dépôt et à la diffusion de documents scientifiques de niveau recherche, publiés ou non, émanant des établissements d'enseignement et de recherche français ou étrangers, des laboratoires publics ou privés. 


\title{
Fluorescent silver oligomeric clusters and colloidal particles
}

\author{
Mona Treguer, Frederic Rocco, Gerald Lelong, Anne Le Nestour, Thierry Cardinal, \\ Abdelhamid Maali and Brahim Lounis
}

\begin{abstract}
:
Highly luminescent single colloidal silver nanoparticles under blue excitation were detected. The intense luminescence observed from the single particles is attributed to different emissive centers. Picosecond lifetimes of those single nano-objects have been measured. Comparison with colloidal particles emission formed in aqueous solution, using polyacrylate polyanion as stabilizer is drawn. The optical properties of silver colloidal particles in solution are observed while their surface is changed by deposition of silver ion. A large visible emission under UV or surface plasmon region excitations is observed for $\mathrm{Ag}_{n} @ \mathrm{Ag}^{+}$, while no fluorescence emission was found for $\mathrm{Ag}_{n}$ or $\mathrm{Ag}^{+}$systems. The intense visible light emission changes should primarily come from chemical surface active sites. It was observed that the oligomeric clusters, composed of only few atoms $\mathrm{Ag}_{4+x} x$ I and $\mathrm{Ag}_{7}{ }^{31}$, have a substantial emission in the same visible region. A model which ascribes the photoemission of the chemically modified silver colloidal particle to oligomeric clusters on the Ag particle surface is proposed. Those emissive water soluble silver clusters have potential for biological labelling, and light emitting sources in nanoscale optoelectronics applications.
\end{abstract}

Keywords: Luminescence; Spectroscopy; Silver nanoparticles; Cluster; Optical microscopy; Photoactivation

\section{Introduction}

The physical properties of nanoparticles of noble metals have been widely studied for several years, in parallel to the efforts which have been devoted for the understanding of their elaboration and their nature. Besides their useful for biological labelling [1], [2] and [3] and their ability to promote surface enhanced optical phenomena [4], [5] and [6], it was discovered that noble metal clusters display intense visible luminescence. The appearance of their strong luminescence are expected to yield new insights into the practical applications in integrated optical devices (optical storage) or in biology (sensors). In the case of silver, it was shown that neutral clusters $\mathrm{Ag}_{m}$ ( $m=2$ to 10) emit light in rare gas matrix at cryogenic temperature [7] and [8]. Dickson [9] and Tominaga et al. [10] have also observed the luminescence from silver oxide films or powders photoactivated or electroactivated. In those latter cases, the observed luminescence has been attributed to photoreduction processes at the interface between metallic silver and silver oxide leading to the presence of silver clusters [11]. Similar investigations on luminescence of a metallic particle and silver charge aggregate have been carried out in solid state materials [12], [13] and [14]. Yet the origin of the observed luminescence is not clearly identified. In most cases, the involvement of small silver clusters such as $\mathrm{Ag}_{2}{ }^{+}, \mathrm{Ag}_{3}{ }^{2+}$ in the vicinity of the surface of larger metallic particles in the luminescence process is hypothesized. However, it is still unclear what mechanisms and structural factors are responsible for the emission of visible light in silver system.

In this paper, we address this problem by investigating the luminescence properties of single colloidal silver nanoparticles. Fluctuations in the emission of the single particles suggest different emission centers and mechanisms. In the mean time, the luminescence 
properties of silver colloidal particles and clusters in aqueous polyanion solutions have been investigated. The optical change, both in absorption and emission, which occurs during the $\mathrm{Ag}^{+}$silver ion addition onto silver colloidal particles are described. Of particular interest is the interaction of the initially deposited $\mathrm{Of}^{+} \mathrm{g}^{+}$with the underlying silver lattice, how they perturb the optical properties of the silver particles. Initially no fluorescence is observed from colloidal $\mathrm{Ag}_{n}$. When $\mathrm{Ag}^{+}$is admitted to the solution, one finds an intense luminescence in the visible region. Similar luminescence is observed for oligomeric clusters composed of only few atoms. The optical changes observed for $\mathrm{Ag}_{n} @ \mathrm{Ag}^{+}$are interpreted in terms of chemical reorganisation at the surface which leads to the formation of charge oligomeric clusters at $\mathrm{Ag}_{n}$ surface.

\section{Experimental section}

The radiolytic method employed here for the preparation of the silver colloid solution leads to a well-defined pathway for the reduction of silver ions into charge silver clusters of small nuclearity and colloidal silver particles [15], [16] and [17]. The method allows to produce a known concentration of reducing or oxidizing radicals in the aqueous solution and to let the radicals transfer an electron into the colloidal metal particles. The methods have important advantages in comparison with chemical redox experiments: they are very reproducible, a minimum of disturbing impurities is introduced, and the reactions are initiated homogeneously. Ionizing radiation produces hydrated electrons and hydroxyl radicals. The hydrated electrons are very strong reducing agents which reduce dissolved metal ions, thus produced atoms. The oxidizing $\mathrm{OH}$ radicals can be converted into reducing organic radicals in the presence of alcohol:

$$
\begin{aligned}
& e_{\mathrm{aq}}^{-}+\mathrm{Ag}^{+} \rightarrow \mathrm{Ag}^{\circ}, \\
& \mathrm{OH}^{*}+\mathrm{R}-\mathrm{CH}_{2} \mathrm{OH} \rightarrow \mathrm{H}_{2} \mathrm{O}+\mathrm{RC}^{*} \mathrm{HOH}
\end{aligned}
$$

Thus, by exposing a deaerated silver salt solution $\left(10^{-4} \mathrm{~mol} . \mathrm{I}^{-1}\right)$ containing $0.1 \mathrm{~mol}^{-\mathrm{I}^{-1}}$ alcohol to $y$-rays, the silver is reduced to form colloidal aggregates. A polyanion $\left(10^{-1}\right.$ $10^{-3} \mathrm{~mol}^{-1}$ ) in the solution stabilized the aggregates. All reagents were of the highest purity available: silver salt $\mathrm{Ag}_{2} \mathrm{SO}_{4}$ was from Aldrich, 2-propanol from Prolabo. Milli-Q grade water was used in all the preparations and the reactants. Depending on the conditions, either metallic silver particles of several nanometer in diameter or very small oligomeric clusters are stabilized. All the solutions were prepared in a glass vessel, which carried a sidearm with an optical cuvette. Deaerated $\mathrm{NaBH}_{4}$ or $\mathrm{Ag}^{+}$were added to the $\mathrm{Ag}$ sol without exposure to air. The absorption and emission spectra were measured at various times after irradiation to ${ }^{137} \mathrm{Cs} y$ source $\left(1.8 \mathrm{kGy} \cdot \mathrm{h}^{-1}\right)$ in a commercial spectrophotometer and spectrofluorimeter. Excitation and emission spectra have been recorded using a system equipped with double monochromators, a xenon lamp for excitation and photomultiplier allowing detection from 200 to $800 \mathrm{~nm}$.

For the single colloidal particles imaging, in order to avoid silver-stabilizer interaction, an alternative method for colloidal metal particles synthesis was used. Silver ions $\left(10^{-3} \mathrm{M}\right)$ was added slowly in a solution of $\mathrm{NaBH}_{4}\left(1.5 \times 10^{-3}\right)$ under vigorous stirring [18]. Samples prepared by this way exhibit a large size distribution with particles from few nanometers to $50 \mathrm{~nm}$ and a large plasmon resonance centered at $430 \mathrm{~nm}$. For single particle imaging and spectroscopy by a scanning confocal microscope, samples were prepared by spin-coating the silver colloids solution on a glass coverslips. Excitation was performed with an Argon ion laser at $476 \mathrm{~nm}$. The laser was focused by $100 \times$ Oil immersion objective $(\mathrm{NA}=1.4)$. Piezo-scanner was used to scan the sample and to position nanoparticles under the focused light. Luminescence of the colloids is sent through a 50/50 beam splitter to a single photon counting module for imaging and on a 
spectrometer equipped with nitrogen cooled CCD detector for luminescence spectra recording.

All the particles elaborated were observed in an electron microscope, Jeol instrument (JEM2000FX), operating at $200 \mathrm{kV}$; samples were prepared by putting a copper-carbon grid on a drop of the solution on oil paper and letting the drop dry almost completely.

\section{Results}

\subsection{Single metallic particle luminescence}

Fig. 1 shows a luminescence image from individual silver nanoparticles spin-coated on a glass at atmosphere conditions under blue excitation. Clearly, the different particles display a multitude of colors. The time traces of the light emitted from single nanoparticles display strong intensity fluctuations and blinking (results not shown). Moreover, the luminescence spectra change from particle to particle as clearly shown in Fig. 2a-d. Despite the Raman lines at 515 and $555 \mathrm{~nm}$, for which the positions follow the excitation wavelength, three distinct broad bands around 550, 600 and $650 \mathrm{~nm}$ are observed. The relative weight of these bands depends on the silver particle. A time correlated single photon measurement to deduce the luminescence lifetime of single particles has been performed. The results showed a decay time shorter than our instrumental resolution ( $<38 \mathrm{ps}$ ). The luminescence results were compared to those of a bulk sample of silver oxide powder photoactivated at $476 \mathrm{~nm}$ (Fig. 2e). The sample exhibits a broad spectrum with multiple components in the whole visible spectrum. Its luminescence is found to increase in time, which is a signature of a continuous formation of emission sites.

\subsection{Optical properties of colloidal $\mathrm{Ag}_{\mathrm{n}}$ particles in solution}

The irradiation of silver ion in the absence of air and in the presence of a polymer leads to silver colloidal particles displaying the well-known Mie resonance around $400 \mathrm{~nm}$ (Fig. 3 ). The wavelength of the plasmon absorption maximum is strongly influenced by chemical modifications of the surface and by an increase of the Fermi level due to a large electron charge density [17]. The spectrum of colloidal silver is altered by addition of borohydride ion in the solution when the reduction of $\mathrm{Ag}^{+}$has been uncompleted, since an increase in intensity and a blue-shift in the $400 \mathrm{~nm}$ band was observed (Fig. 3b). On the other hand, the deposition of silver ions or oxygen on silver sol completely reduced leads to a red-shift of the resonance plasmon band (Fig. 3c). The changes in the electron density of the particle are reversible and have been used as sensitive indicators for the occurrence of an interaction between the metal particles and a dissolved substract. Luminescence experiments were carried out on similar silver sol: uncompletely reduced, completely reduced with $\mathrm{NaBH}_{4}$, and subsequently modify with $\mathrm{Ag}^{+}$. Whereas an intense and broad emission in the visible (550-750 nm) for excitation at $300 \mathrm{~nm}$ for $\mathrm{Ag}_{n} @ \mathrm{Ag}^{+}$or $\mathrm{Ag}_{n}$ uncompletely reduced (Fig. 4), one finds that the luminescence is almost quenched for completely reduced silver sol (not shown). In this latter case, the fairly weak remaining emission at 450 and $650 \mathrm{~nm}$, observed for excitation between 300 to $350 \mathrm{~nm}$, is at the limit of our detection system. It is attributed to the interaction of the carboxyl group of the stabilizing polymer and $\mathrm{Ag}^{+}$, since similar weak emission is observed on the solution before $y$-rays irradiation. Important change of polymer electronic structure in the presence of silver was already noticed by Mostafavi et al. [19]. The highly intense and broad luminescence observed for $\mathrm{Ag}_{n} @ \mathrm{Ag}^{+}$or uncompletely reduced $\mathrm{Ag}_{n}$ solution display two majors components around 550 and $700 \mathrm{~nm}$. Note that the emission intensity increases with the addition of silver ions with no significant fluctuation of the spectra under our spectral resolution $(10 \mathrm{~nm})$. The emission and excitations spectra, shown on Fig. 4, clearly indicate two emission components corresponding to two different excitation wavelength domains. The large emission located around $700 \mathrm{~nm}$ corresponds to 
excitation wavelengths between 280 to $300 \mathrm{~nm}$; whereas the less intense one around $550 \mathrm{~nm}$ appears for excitation in 300-400 $\mathrm{nm}$ region. One also finds that the both emission are also observed for excitation in the wavelength domain corresponding to surface plasmon resonance of the silver sol (from 450 to $600 \mathrm{~nm}$ ). These findings may indicate the presence of two distinct emission centers or one center with complex excited state structure. In addition, since the visible emission is also observed for excitation in the plasmon resonance frequencies of the silver sol, a strong coupling between the $\mathrm{Ag}_{n}$ colloidal particles and the emissive center(s) is expected.

\subsection{Optical properties of oligomeric silver clusters in solution}

As previously outlined, oligomeric silver clusters can be radiolytically produced in aqueous solution in presence of sodium polyacrylate as stabilizer. The exact nature of the clusters is not fully understood [15]. Nevertheless, pulse radiolysis investigations as well as steady state experiments have given reason for the agglomeration number of the clusters being smaller than 10. The silver clusters, $\mathrm{Ag}_{4+x}{ }^{x+}$ and $\mathbf{A g}_{7}{ }^{3}$, have been prepared. They, both, display absorption band at wavelengths shorter than the plasmon band of the larger metallic particles (Fig. 5). The absorption bands from 260 to $350 \mathrm{~nm}$ correspond to intrinsic absorption of the clusters, while the large ones respectively around $470 \mathrm{~nm}$ for $\mathrm{Ag}_{4+x}{ }^{x+}$ and at $580 \mathrm{~nm}$ for $\mathrm{Ag}_{7}{ }^{3+}$ are related to the cluster-polymer interaction. The $\mathrm{Ag}_{7}{ }^{3+}$ clusters solution are stable for many weeks, whereas, the $\mathrm{Ag}_{4+x}{ }^{x+}$ ones only are stable for few hours. When they disappear, they give rise to larger oligomeric clusters. The color solution turns from pink to blue, characteristic of $\mathrm{Ag}_{7}{ }^{3+}$ clusters. Due to the low stability, we cannot exclude that the shoulder of the absorption spectrum of $\mathrm{Ag}_{4+\lambda} x+$, around $600 \mathrm{~nm}$, correspond to a few larger $\mathrm{Ag}_{7}{ }^{3+}$ clusters. In order to increase the lifetime of the $\mathrm{Ag}_{4+x}{ }^{x+}$ clusters and facilitate the optical investigation, an evaporation of the solvent under vacuum was conducted. The resulting material was deposited on fused quartz flakes and further grinded. Despite its stability, a similar process has been applied to the $\mathrm{Ag}_{7}{ }^{3+}$ silver cluster solution to validate the sample preparation. The emission and excitation spectra obtained for $\mathrm{Ag}_{7}{ }^{3+}$ remains identical before and after evaporation.

Fig. 6 reports the emission and excitation spectra of $\mathrm{Ag}_{7}{ }^{3+}$ and $\mathrm{Ag}_{4+x}{ }^{x \mid}$ clusters once deposited. The $\mathrm{Ag}_{7}{ }^{3}$ । solution or deposited on silica flakes exhibit a similar emission centered at $700 \mathrm{~nm}$ for excitation around $300 \mathrm{~nm}$ (Fig. 6a). This excitation wavelength corresponds to the intrinsic absorption of the silver cluster. In the case of $\mathrm{Ag}_{4+x} x+$ clusters, an emission is also observed at $700 \mathrm{~nm}$ for excitation around $300 \mathrm{~nm}$ while emission at shorter wavelength around $550 \mathrm{~nm}$ can be observed for excitation above 300 $\mathrm{nm}$. The excitation band observed either correspond to the absorption band of $\mathrm{Ag}_{4+x} x+$, centered at 280 and $350 \mathrm{~nm}$ [19] or to a $\mathrm{Ag}_{4+x}{ }^{2+}$ with a few amount of $\mathrm{Ag}_{7}{ }^{3}$ ।.

\section{Discussion}

The ensemble of those results gives new insights in the visible luminescence of silver.

(a) The single particle imaging and spectroscopy experiments suggest that different luminescent centers such as $\mathrm{Ag}_{m} \mathrm{O}_{x}$ clusters (with $m<10$ ) are produced from the same single nano-sized $\mathrm{Ag}_{n}$ particles. Indeed, since the luminescence only occurs in the presence of air (not under inert atmosphere), one suggests that a partial oxidation of the silver leads to the formation of $\mathrm{Ag}_{m} \mathrm{O}_{x}$ clusters on the $\mathrm{Ag}_{n}$ surface. Furthermore, the 
photoactivation of $\mathrm{Ag}_{2} \mathrm{O}$ film leads to the spectrum of Fig. 2e which is overlaying those measured on single $\mathrm{Ag}_{n}$ particles (Fig. $2 \mathrm{a}-\mathrm{d}$ ). The same bands could be distinguished. These observations are in accordance with previously reported study which assigned the emissive sites to small silver clusters (of few atoms) photo-activated by light illumination [20]. Since the photoactivation of $\mathrm{Ag}_{2} \mathrm{O}$ produce silver clusters and irradiation of $\mathrm{Ag}_{m} \mathrm{O}_{x}$ on nanometer sized silver leads to similar optical response, one suggests similar origin and sites for the luminescence: $\mathrm{Ag}_{m} \mathrm{O}_{x}, \mathrm{Ag}_{m}$ clusters, coupled with $\mathrm{Ag}_{n}$ particles. The coupling of the particle and the clusters leads to a stabilization of the clusters as well as possible interaction between the plasmon resonance and the clusters luminescence. The short lifetime recorded traduces also such coupling effect. Such shortening of the fluorescence lifetime of dyes or of silver entities at silver particles surface, has previously been observed [21] and [22].

(b) The experiments performed on colloidal and oligomeric silver particles in solution provide more informations on the nature of the emissive centers. In solution, the emission of silver particles is only observed in the presence of silver $\mathrm{Ag}^{+}$. The broad emission from 500 to $800 \mathrm{~nm}$ with major components, at 550 and $700 \mathrm{~nm}$ are observed for an excitation in the UV region or in the surface plasmon resonance. The excitation spectra in the UV region between 270 and $400 \mathrm{~nm}$ are close to the absorption of charge oligomeric clusters of small nuclearity, $\mathrm{Ag}_{m}{ }^{x+}$. In addition, strong similarities exist between the luminescence response of the oligomeric clusters and $\mathrm{Ag}_{n} @ \mathrm{Ag}^{+}$sol.

Therefore, one suggests that upon addition of $\mathrm{Ag}^{+}$on $\mathrm{Ag}_{n}$ sol, oligomeric clusters $\mathrm{Ag}_{m}{ }^{x+}$ are formed on the surface of the nano-sized metallic particles. The exact nature and size of the oligomeric clusters formed on the surface of the $\mathrm{Ag}_{n}$ sol is still unclear, since the assignment of the emission and the related excitation band is complex. For tentatively evidence the presence of the oligomeric clusters at the surface of the silver sol, Fig. 7 shows the difference between absorption spectra of $\mathrm{Ag}_{n}$ sol after addition of various amounts of $\mathrm{Ag}^{+}$ions $(200 \mu \mathrm{l})$. The differential spectrum is comparable to the absorption spectrum of oligomeric clusters $\mathrm{Ag}_{4+m}{ }^{x \mid}$ with probably a few amount of $\mathrm{Ag}_{7}{ }^{3+}$, except in $260 \mathrm{~nm}$ region. The band in $260 \mathrm{~nm}$ region is assigned to the charge transfer band of $\mathrm{Ag}^{+}$-polymer. According to those observations, one suggests that optical change accompanying the chemisorption of silver ions to $\mathrm{Ag}_{n}$ particles is regarded to chemical reorganisation of the surface which leads to the formation of oligomeric clusters. The change of electronic properties of the particles earlier studied by Henglein and coworkers is probably not the only cause of optical changes [17]. Quantitative theoretical model for the effect of chemisorption molecules on metal particles is thus highly desirable.

In conclusion, strong luminescence similarities in the visible region are observed from oxidized silver clusters on silver nanoparticles and nano-sized silver particles in solution exposed to silver ion. The coupling effect induces short fluorescent lifetimes of the colloidal silver particles. Comparison with the luminescence of oligomeric silver clusters has been drawn. It is proposed that charge oligomeric clusters $\mathrm{Ag}_{4} \mid x^{x+}$ and $\mathrm{Ag}_{7}{ }^{3+}$ are formed upon addition of $\mathrm{Ag}^{+}$on nano-sized $\mathrm{Ag}_{n}$ particles in solution. The oligomeric clusters are responsible for the strong and intense luminescence observed in the visible region. The luminescence of those nano-objects may offer the possibility of applications for optronics as optical memory elements and in biological labelling. Further investigations are in progress to narrow the size distribution of $\mathrm{Ag}_{n}$ particles and to photo-chemically control the fluorescent spectral features of these coupled systems.

\section{References}

[1] H. Geerts, M. de Brabander and R. Nuydens, Nature 351 (1991), pp. 765-766. 
[2] J.F. Hainfeld and R.D. Powell, J. Histochem. Cytochem. 48 (2000), pp. 471-480.

[3] S. Schultz, D.R. Smith, J.J. Mock and D.A. Schultz, P.N.A.S. 97 (2000), pp. 9961001.

[4] W.E. Doering and S. Nie, J. Phys. Chem. B 106 (2002), pp. 311-317.

[5] S. Nie and S.R. Emory, Science 275 (1997), pp. 1102-1106.

[6] K. Kneipp, Y. Wang, H. Kneipp, L.T. Perelman, I. Itzkan, R.R. Dasari and M.S. Feld, Phys. Rev. Lett. 275 (1997), pp. 1102-1106.

[7] C. Félix, C. Sieber, W. Harbich, J. Buttet, I. Rabin, W. Schulze and G. Ertl, Phys. Rev. Lett. 86 (2001), p. 2992.

[8] L. König, I. Rabin, W. Schultze and G. Ertl, Science 274 (1996), p. 1353.

[9] L.A. Peyser, A.E. Vinson, A.P. Bertko and R.M. Dickson, Science 291 (2001), pp. 103-106.

[10] C. Mihalcea, D. Büchel, N. Atoda and J. Tominaga, J. Am. Chem. Soc. 123 (2001), pp. 7172-7173.

[11] T.H. Lee, J.I. Gonzalez and R.M. Dickson, P.N.A.S. 99 (2002), pp. 10272-10275.

[12] Y. Watanabe, G. Namikawa, T. Onuki, K. Nishio and T. Tsuchiya, Appl. Phys. Lett. 78 (2001) (15), pp. 2125-2127.

[13] I. Belharouak, F. Weill, C. Parent, G. Le Flem and B. Moine, J. Non-Cryst. Solids 293- 296 (2001), pp. 649-656.

[14] G. Le Flem, A.V. Podlipensky, V. Grebenev, G. Seifert and H. Graener, J. Luminescence 109 (2004), p. 135.

[15] A. Henglein, P. Mulvaney and T. Linnert, Faraday Discussion 92 (1991), pp. 31-44.

[16] M. Mostafavi, N. Keghouche, M.O. Delcourt and J. Belloni, Chem. Phys. Lett. 167 (1990) (3), p. 193.

[17] A. Henglein, J. Phys. Chem. 97 (1993), p. 5457.

[18] J. Creighton, C. Blatchford and M. Albrecht, J. Chem. Soc. Faraday Trans. II 75 (1979), p. 790.

[19] M. Mostafavi, M.O. Delcourt, N. Keghouche and G. Picq, Radiat. Phys. Chem. 41 (1993) (3), pp. 453-459.

[20] J. Zheng and R.M. Dickson, J. Am. Chem. Soc. 124 (2002) (13), p. 982.

[21] A. Leitner, M.E. Lippitsch, S. Draxler, M. Riegler and F.R. Aussenegg, Appl. Phys. B 36 (1985), pp. 105-109.

[22] V.P. Kamat, Chem. Rev. 93 (1993), pp. 267-300. 


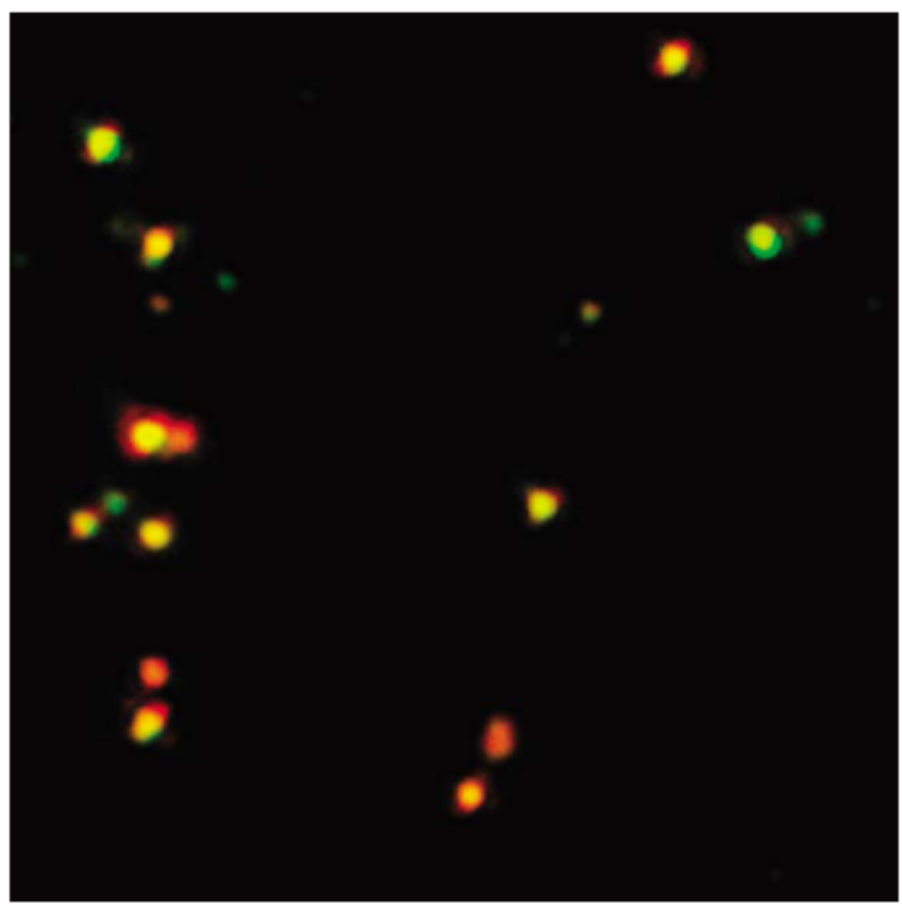

Fig. 1. $10 \mu \mathrm{m} \times 10 \mu \mathrm{m}$ luminescence image of silver nanoparticles spin-coated on glass cover slips. The image was taken with Nikon camera within 1 second exposure time. Continuous wave excitation at $476 \mathrm{~nm}$ was provided by Ar ion laser. A holographic notch filter (Kaiser Optics) was used to reject the scattered laser light.

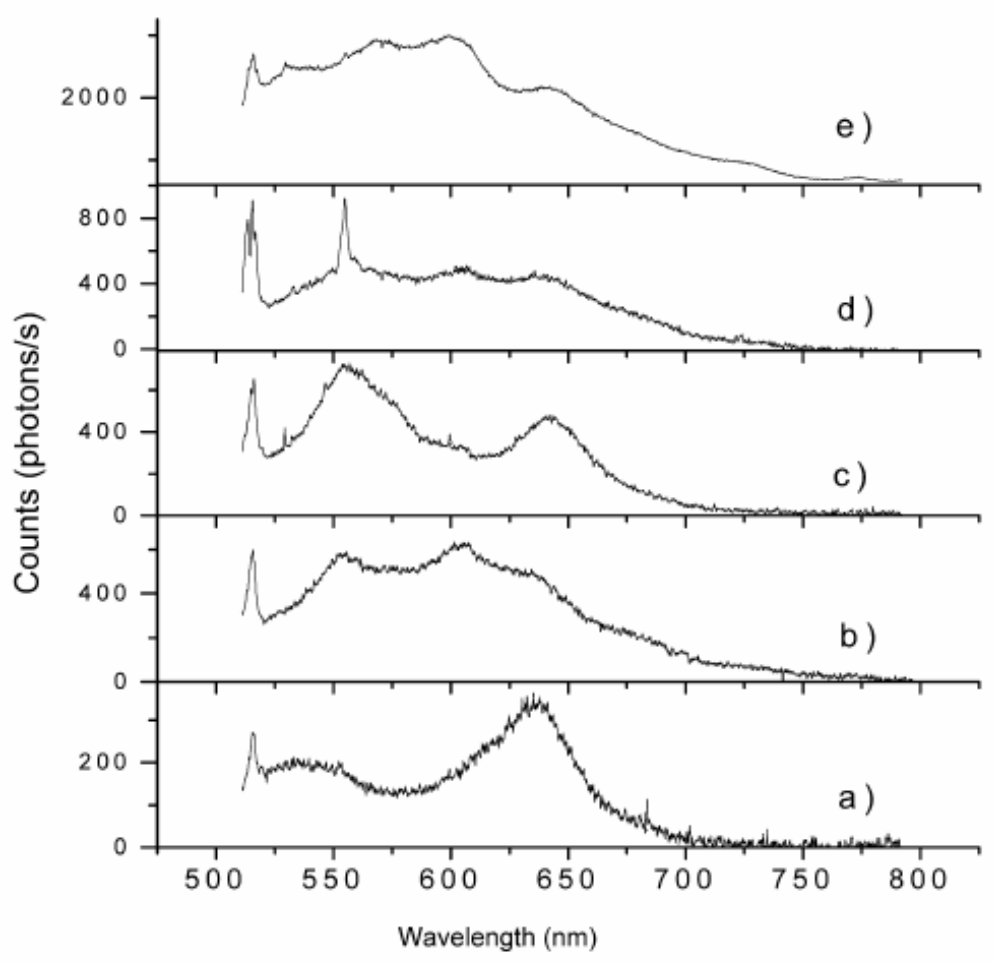

Fig. 2. a)-d): Luminescence spectra of four different single silver particles collected on the same sample. Excitation intensity $=10 \mathrm{~kW} / \mathrm{cm}^{2} ;$ integration time $=200 \mathrm{~s}$. e): Luminescence spectrum of silver oxide powder (Aldrich, Purity $99.99 \%$ ) under laser illumination at $476 \mathrm{~nm}$. 


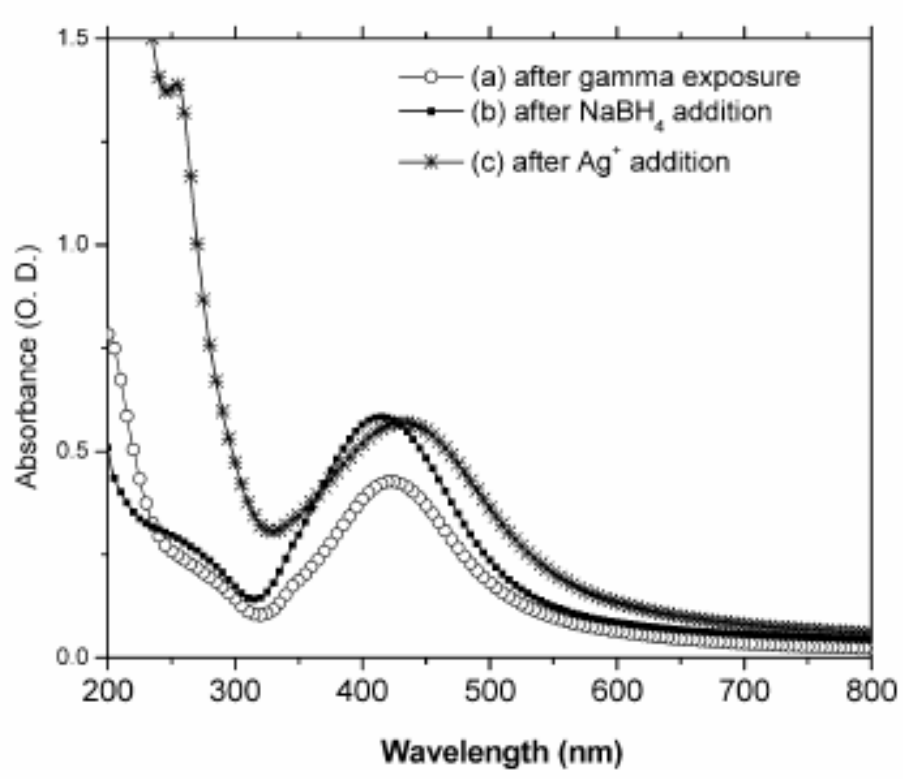

Fig. 3. Absorption spectra of silver colloidal particles. (a) $10^{-4} \mathrm{M} \mathrm{Ag}^{+}$solution - uncompleted radiolytical reduction, (b) after addition of $\mathrm{NaBH}_{4}$, (c) after addition of $50 \times 10^{-6} \mathrm{M} \mathrm{Ag}{ }^{+}$in solution. $\left[\mathrm{Ag}^{+}\right]=10^{-4}$; $[\mathrm{APA}]=10^{-2} \mathrm{M}\left(\mathrm{MW}=10^{4}\right)$; $[$ isoOH $]=0.2 \mathrm{M} ; \mathrm{pH}=6.2(\mathrm{NaOH})$; irradiation dose: $0.60 \mathrm{kGy} . l=1 \mathrm{~cm}$.

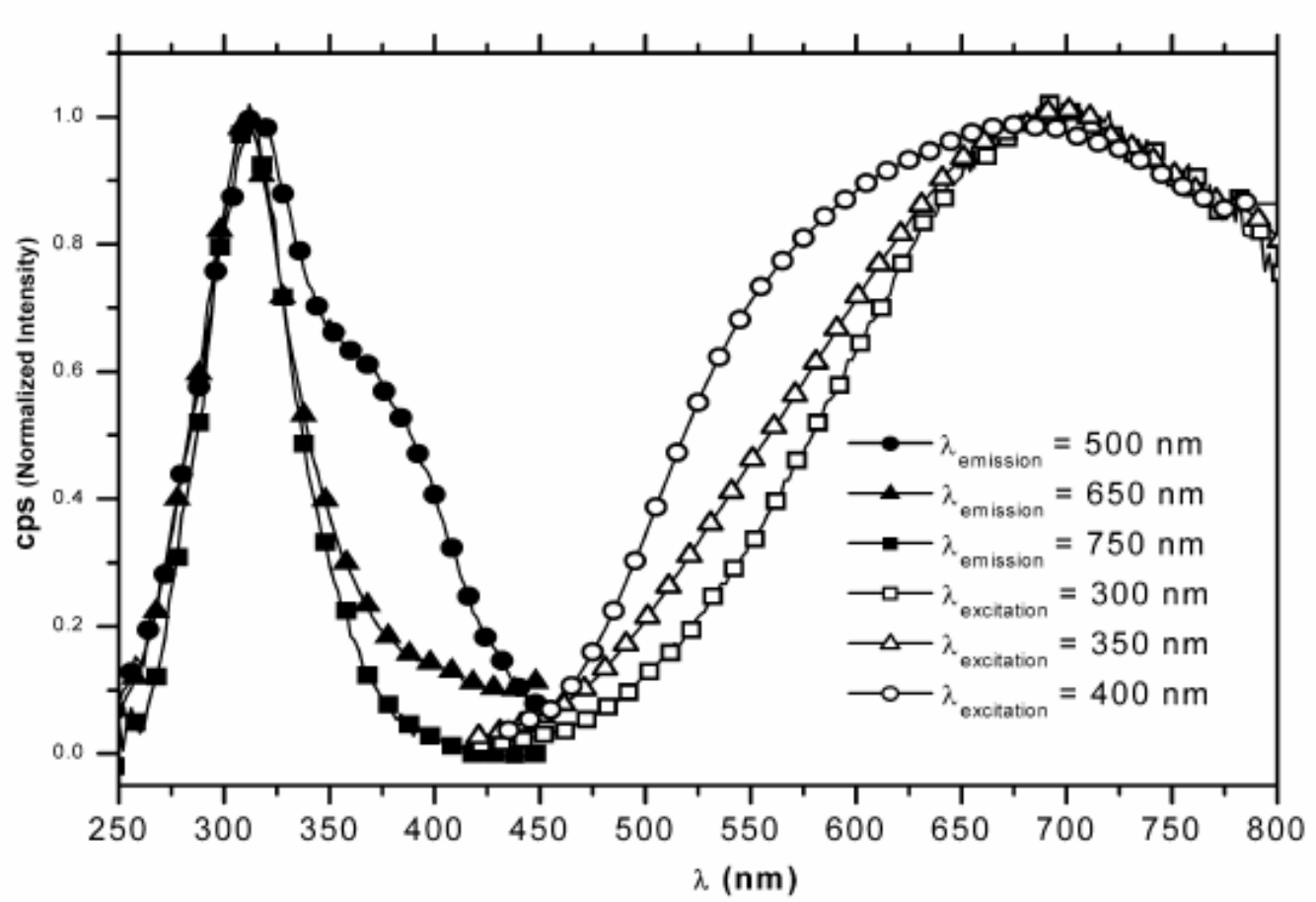

Fig. 4. Excitation and emission spectra of colloidal silver. Experimental conditions identical to Fig. 3. 


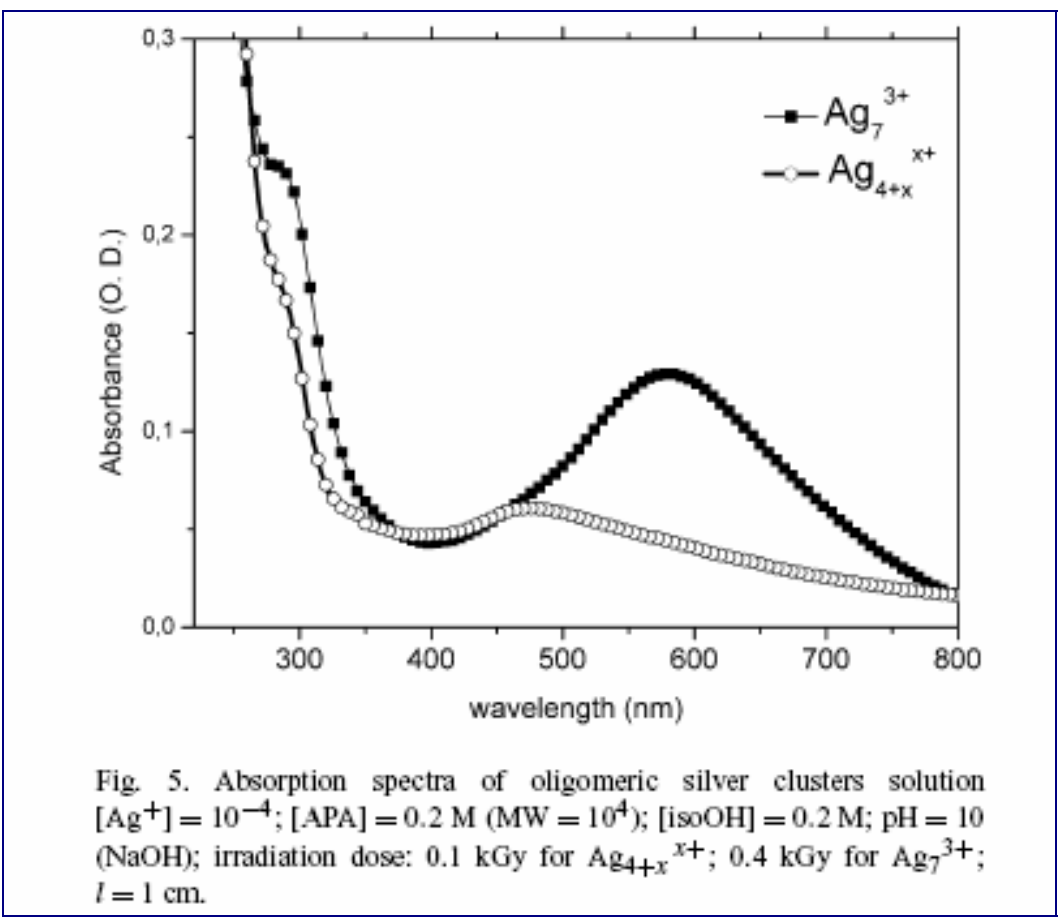




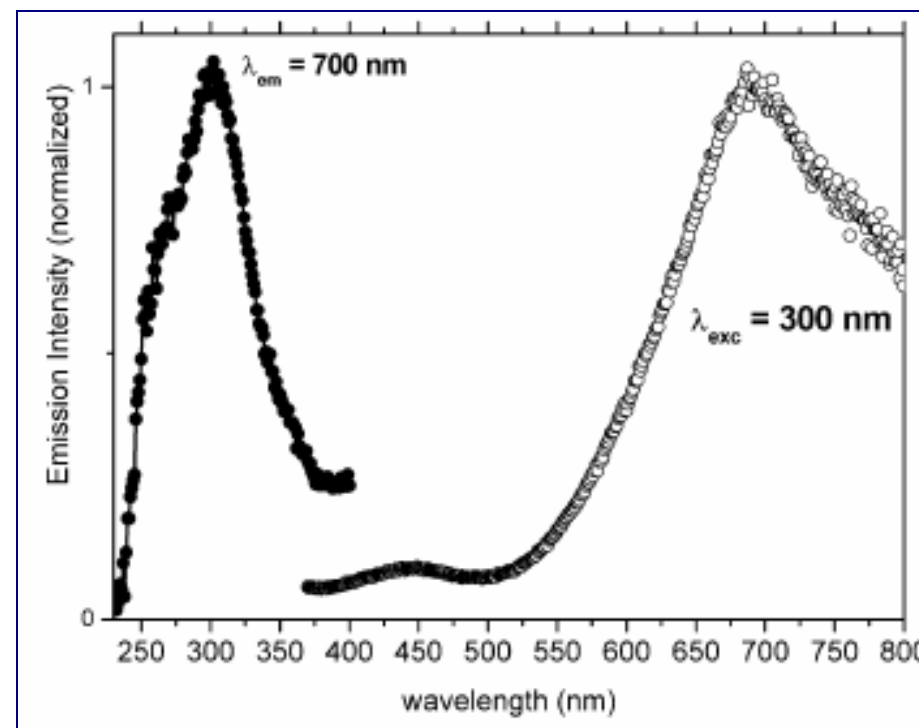

(a)

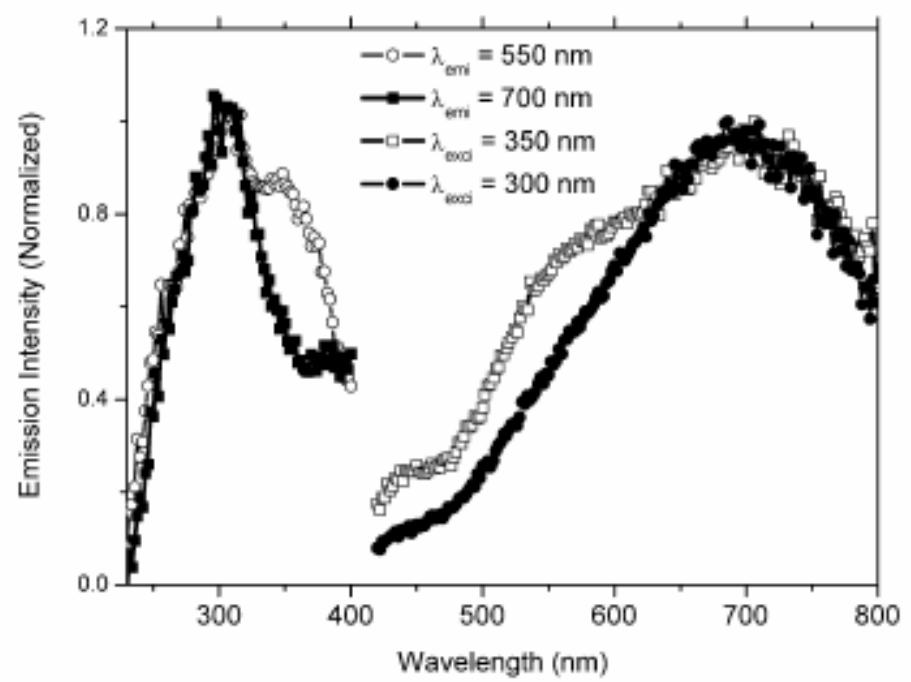

(b)

Fig. 6. Excitation and emission spectra of oligomeric silver clusters solution (a) $\mathrm{Ag}_{7}^{3+}$, (b) $\mathrm{Ag}_{4+x} x+$. Experimental conditions identical to Fig. 5 . 


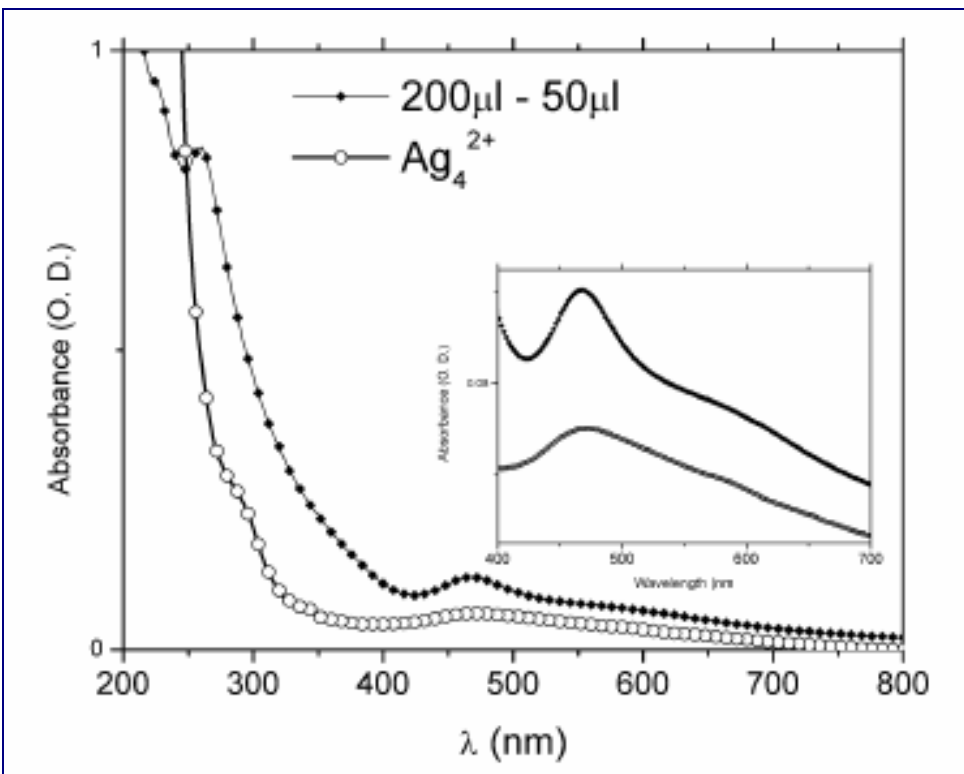

Fig. 7. Absorption spectra difference of silver sol after addition of $200 \mu \mathrm{l}$ and $50 \mu \mathrm{l} \mathrm{of} \mathrm{Ag}^{+}$ion $\left(10^{-2} \mathrm{~mol} \cdot \mathrm{l}^{-1}\right) .0$ Absorption spectrum of $\mathrm{Ag}_{4+x}{ }^{x+}$ solution. $l=1 \mathrm{~cm}$. 